\title{
From climate adaptation to climate justice: Critical reflections on the IPCC and Himalayan climate knowledges
}

\author{
Ritodhi Chakraborty ${ }^{1}$ (D) Pasang Yangjee Sherpa ${ }^{2}$
}

Received: 13 January 2021 / Accepted: 25 June 2021/ Published online: 23 August 2021

(C) The Author(s), under exclusive licence to Springer Nature B.V. 2021

\begin{abstract}
The IPCC reports represent a powerful discursive and institutional undertaking. However, the IPCC has faced criticism for its different organizational and functional biases which include a geographical bias favoring experts from the global north, a gender bias in favor of men, a disciplinary bias in favor of the natural sciences over the social sciences and humanities, and finally, a cosmological bias favoring western science over indigenous knowledges. In recent years, scholars have noted changes in the IPCC, pointing at the inclusion of social science/humanities perspectives and a growing engagement with plural worldviews. Despite such forays, all aspects of knowledge production within the IPCC still echo the aspirations of nation states and quantitative models of attribution and detection. Climate knowledge production in the Himalayan region reflects this reality. In this essay, we focus on our personal experiences with local communities from the Himalayas and bring it in dialogue with our experiences with the IPCC knowledge production process. In doing so, we have two objectives: first, to highlight marginalized stories of climate-society relationships that challenge normative climate science/policy and, second, in light of these stories, suggest some salient considerations required to foreground justice and equity in futureengagements with the IPCC, which explores the production of democratic knowledge and how such knowledge can be wielded to achieve regional climate justice.
\end{abstract}

Keywords Climate adaptation $\cdot$ Climate justice $\cdot$ Climate knowledges $\cdot$ Himalayas

This article is part of the topical collection "Climate Change Communication and the IPCC", edited by Saffron O'Neill and Roz Pidcock.

Ritodhi Chakraborty

Ritodhi.chakraborty@lincoln.ac.nz

1 Centre of Excellence (DFPL), Faculty of Agriculture and Life Sciences, Lincoln University, Lincoln 7647, New Zealand

2 Pacific Lutheran University, 12180 Park Ave S, Tacoma, WA 98447, USA 


\section{Introduction}

Over the past 30 years, the Intergovernmental Panel on Climate Change (IPCC) has emerged as a powerful institution within the area of global environmental assessments. It advocates for a scientific and political focus on climate change as the foremost body of climate knowledge production; positions itself as a translator of global environmental change at multiple sciencepolicy nodes of engagement; and provides a platform for the governments of about 195 nationstates to take an active part in the establishment of climate change research questions and priorities. Informed by the insights of IPCC reports, two significant agreements have been produced: the Kyoto Protocol in 1997 and the Paris Agreement in 2015. The institution has also inspired the intellectual and organizational elements of other multi-stakeholder science-policy initiatives such as the Intergovernmental SciencePolicy Platform on Biodiversity and Ecosystem Services (IPBES) (IPCC 2014). However, the IPCC which consists of an international group of scientists has faced criticism for different organizational and functional biases which include a geographical bias favoring experts from the global north, a gender bias in favor of men, a disciplinary bias in favor of the natural sciences over the social sciences and humanities, and a cosmological bias favoring western science over indigenous knowledges (Beck and Mahony 2018; Gustafsson and Berg 2020; Mach et al. 2017; Mahony 2014; Vardy et al. 2017).

Addressing such concerns is critical for the pursuit of multi-scalar and multi-temporal representation and justice within the contentious narratives defining nature-society relationships. Scholarship on the history, politics, and philosophy of science has challenged the valueneutral conceptualizations of climate science, arguing that the IPCC is an organization involved in boundary work and is a boundary organization (Hoppe et al. 2013; Livingston and Rummukainen 2020; De Pryck and Wanneau 2017). Boundary work can be understood as the efforts of the various subjects and institutions of the science and policy spheres to characterize the lines separating them while also trying to form a collaborative work culture to address the complicated issues that span across such lines. In its most fundamental definition, it relates to the actions and processes that create, maintain, and destroy boundaries for the production and management of knowledge (Bremer and Meisch 2017). In climate science, boundary work has often been performed to satisfy the empirical aspirations of biophysical scientists and the political aspirations of various nation-states. Therefore it encompasses the wielding of power to define who or what is legitimate (knowledge, stakeholder) and belongs within a certain group (e.g., climate change experts, historical national emission responsibilities). Ultimately, the boundary separating science and politics is frequently negotiated and renegotiated. The IPCC as a boundary organization sits at the edges of diverse sociomaterial positions and exhibits very specific versions of accountability towards each. And it employs boundary objects - items or artifacts of knowledge that can be adjusted and utilized across different socio-political contexts for different goals (e.g., temperature targets like $2{ }^{\circ} \mathrm{C}$ or $1.5^{\circ} \mathrm{C}$ ). Over the years, the IPCC's role as a boundary organization and its attempts at managing the plural aspirations of its stakeholders has led to its conceptual positions around scientific objectivity, socio-political positions around formalization and standardization of procedure, and a spatial position skewed towards the global north reflecting existing geopolitical power discrepancies. Such an institutional culture creates a significant set of issues concerning just and democratic knowledge production across the world (Beck and Mahony 2018; Carey et al. 2014; Minx et al. 2017; Pearce et al. 2018). 
In the Himalayas, questions of representation and justice have marred science and policy regarding climate change (Ensor et al. 2019; Nightingale 2016; Ojha et al. 2020a, b; Satyal et al. 2017; Sherpa 2014). Such critiques are rooted in a rich vein of critical and radical social science and humanities scholarship on nature-society relations that seek to interrogate environmental determinist narratives of risk, techno-managerial decision-making pathways, hegemonic state development policies, geopolitical contentions at multiple borderlands, and the active marginalization of the plurality of worldviews that constitute the region (Campbell 2017; Davis et al. 2020; Drew, 2014, b; Gergan 2017; Huber 2019; Joshi 2014; Lord et al. 2020; Ojha 2020; Poudel 2018; Sapkota et al. 2016). This scholarship reveals the insidious nature of the theory of environmental degradation (THED), which still informs critical policy positions and has morphed into a regional narrative of the Anthropocene. It also highlights the complicated manifestations of state power and energy politics through haphazard industrialization which include the construction of a widespread network of dams in the region, and how such infrastructure engages with assessments of risk and vulnerability. Finally, it highlights how transnational climate change management initiatives like the REDD+ program have marginalized historic needs of justice within natural resource governance, through a simplistic focus on carbon and its reduction. This optimization of dynamic human-nature relationships for the removal, capture, and trade of carbon has threatened more participatory and locally rooted management aspirations and cosmologies while ushering in a wide variety of powerful international entities. Most regional climate science and policy emerge from this intersection of risk theory, modern state-building, and algorithm-driven market-orchestrated transnational environmental governance.

In response, in recent years, national governments have attempted to create more inclusive attempts to address the diverse manifestations of climate change within their governance spaces, and intergovernmental initiatives such as the International Centre for Integrated Mountain Development (ICIMOD) have mobilized to explore the place-based, multidimensional narratives of social-ecological change (Awasthi et al. 2016; Mishra et al. 2017). However such attempts are rare, and most climate change knowledge production in the region exhibits biases very similar to those witnessed in the IPCC. Additionally, attempts to address the data poverty and lack of reliable projections advocate for the wide operationalization of the scientific model with very little focus on the powerful historical and political processes that produce regional (transnational) nature-society relationships (Gerlitz et al. 2015; Singh and Thadani 2015). At present, the plurality of Himalayan voices is marginalized both by the political aspirations of the nation-state which fails to represent the aspirations and experiences of its diverse citizens, especially when they threaten its developmental and geopolitical goals, and by the hegemonic narrative of the Anthropocene that erases historical inequities and injustices and replaces them with an overarching "risk society" which afflicts all individuals and communities and can only be resolved through expert-driven initiatives (Chakraborty et al. 2021; Mathur 2015; Nightingale 2017; Ojha et al. 2016).

Given this situation, how does one expose the science-society negotiations underlying the "boundary work" which produces climate knowledge in the region? How do we transform the questions of climate adaptation/mitigation to those of climate justice? To begin with, there is a vital need to reveal the place-based stories of such negotiations that weave together both marginalized and elite subjects and institutions. This process highlights embodied experiences of climate-society relationships and how such relationships are part of a constellation of power. Furthermore, they act as a prism through which to view both the subjectivity of knowledge and the role of institutions like the IPCC in reproducing or challenging certain versions of reality 
(Livingston et al. 2018). Building on this heuristic, in this essay, two early-career scholars, who work in the Himalayan region with issues of social-environmental change and environmental/climate justice, present their experiences of working with Himalayan communities and their engagements with the IPCC.

Here, we hope to address three separate issues. First, we hope to reveal the politics of knowledge in climate change research in the Himalayas. Second, we hope to situate the IPCC within a socio-political context and highlight its potential and its limitations. Third, we hope to present a (concise) vision for the future which prioritizes plural aspirations of environmental and social justice within the arena of climate change science/policy. To do so, in the following two segments, we present ethnographic accounts of the authors' engagements with people and institutions in specific regions of the Himalayas (Uttarakhand, India, and Nepal) that form the empirical core of this essay. These accounts are presented in the first-person voiceand represent respective author experiences. The third segment brings these accounts together to engage with the broader scholarship mentioned in the Introduction.

\section{Ritodhi: "Why are you so interested in the climate? The climate is not what oppresses us"-listening to and telling climate stories}

Uttarakhand (pahar) state of North India lies in the central Himalayan region. The state is largely rural, agrarian, and Hindu. Most paharis (the people of Uttarakhand/literally mountain people) live in villages (and small towns) scattered across a rapidly transforming socialecological landscape. In many of these villages removed from the bustling marketplace and the clusters of wood/stone/concrete houses next to terraced fields, there is a place reserved for the "unfortunate" and the "cursed." These spaces are often filled with widows, people of the lowest caste, and mentally differently abled people. At one such village, in 2016, sitting at the house of one such widow (Ekta), I asked if she had noticed any changes in the rainfall in the past few years. The question was part of a longer list aimed at understanding community perceptions of changes in the climate. In response, she sighed in exasperation and said, "Why are you so interested in the climate?" to which after a moment of silence she added, "...the climate is not what oppresses us." Her adolescent son Sunil who was sitting next to her chimed in, "The village elite are like vultures. They prey on the vulnerable, pushing us further towards death. I mean you know all about it, it all started when my father died on the border." Sunil's father Prakash part of the Indo Tibetan Border Police had died under mysterious circumstances somewhere along India's contentious Himalayan border with China's Tibetan Autonomous Region. In the aftermath of Prakash's death, a violent struggle ensued between his surviving brothers to claim his share of the ancestral land. This led to the ostracization of Sunil and Ekta, who lost their privileges to access subsidized grain, share the communal plowshare, and take part in various village institutions. Sunil stated as a matter of fact:

When members of powerful families die, they are often registered as victims of natural disasters or human-animal encounters. Death certificates are forged, officials are paid off and the deceased's family receives a hefty relief package from the government. On the other hand, we are still waiting for the army pension that we are rightfully owed. So, you tell me, is it better to die fighting in some faraway political war or to drown in a monsoon flood?

Ekta and Sunil's story is not unique, and their frustration is echoed by many different households and communities. The impact of climate change on people's lives in the mountains is a product of their engagements with the historic processes of power and placemaking. 
However, their stories of the climate jostle for legitimacy with different expert narratives, which remain rooted in abstract (and data-poor) scientific models, colonial notions of land management, and techno-managerial inclinations of the developmental state (Mathur 2015; Satyal et al. 2017). During the 2013 monsoons, a multi-day cloudburst over a famous religious tourism spot in Uttarakhand caused a glacier lake to collapse and release its contents. In the subsequent flooding and landslides, over 10000 people died, about 5000 villages were affected, and by some estimates, the total damages incurred by the region were about half a billion US\$ (Kala, 2014). The causes of this event have since been hotly debated by various scholars, aid agencies, and government bodies. While some have called it a "natural disaster," pointing to the powerful and fairly unprecedented precipitation event, others have described it as a "man-made disaster" stating the unmitigated natural resource extraction, industrial infrastructure development (roads, dams) within highly erodible and seismically active mountain lands, and the rapidly growing presence of permanent pahari houses in historical flood plains. For paharis like Sunil, the event remains both a natural and a man-made one. He thinks of the floods as divine retribution for humanity's considerable moral failings. Simultaneously, he sees the event as the latest manifestation of a historical theatre of oppression, orchestrated by the elites against marginalized people and communities. As he eloquently put it, "Did any politicians, or CEOs, or movie stars die in the floods? Nope. It was just poor sods like me...the kings of my grandfather's days have been replaced by crooked politicians and thekedars (government contractors) of today."

A few weeks after leaving Sunil's house in the high mountains, I met with a group of scientists working at a public university in the provisional state capital. The group consisted of geologists, hydrologists, engineers, and experts from various disciplines of the agricultural and environmental sciences. They were quite adamant in claiming that climate change was the greatest threat facing the Himalayas and were quite excited about the newly set up National Mission on Himalayan Studies by the Ministry of Environment, Forest and Climate Change of the Government of India. This initiative had promised to deliver millions of dollars of funding over the next decade to "improve quality of life and maintain ecosystem health of the region to ensure long-term ecological security to the country" (IHCAP 2016). A senior scientist summed up the feelings within the room and said, "The mountains are always neglected. We are the last to get roads and electricity and our problems are always ignored in New Delhi's halls of power. But now with climate change, the whole world's focus is on us. We need to seize this opportunity..." But what about Sunil's story, I asked them, recounting dozens of such interactions from across the state. Is climate change the most pressing need of the hour? Or should we be engaging with the ongoing legacies of structural oppression and inequality? This was met with nervous laughter as some of the younger scientists exchanged furtive glances with each other, almost signaling to me that I had crossed a line. Then the scientist who had spoken before said irritably as if frustrated at my inability to understand the obvious:

We are scientists, we deal with facts. People in the village don't understand all this. Especially young people. They just want to leave the mountains for the plains. Paharis don't have access to a good education and are very superstitious. This is what is holding our region back. What we need is more investment in science and technology so that we can dispel these old stories. We have so many problems with floods, crop production, disasters, wild animals, diseases, etc. and we need to deal with them scientifically... the world over scientists are calling for action on climate change, and we should not get left behind like we usually do in the Himalayas 
A few years after these conversations, I was asked to be a part of the Cross-Chapter paper on Mountains for the IPCC's AR6-WG2 report. The lead authors reached out to me stating that they needed more "inclusion" and "representation" from social scientists working with the human dimensions of climate change that prioritized "local/indigenous knowledge." They added that while the IPCC institutional mandates around knowledge production were quite rigid, there was a degree of processual freedom that was slowly emerging which allowed certain unique customizations within individual chapters of the report. I probed further asking how they hoped to incorporate and represent the narratives rooted in such knowledges, especially since the rubric set up to disseminate individual pieces of scholarship seemed to be unaware of the contentious nature of climate knowledge production that I had encountered in the Himalayas. Additionally, I wanted to understand if there was space within their frameworks of detection and attribution to adequately represent the diversity of climate change narratives that emergently constituted their conceptual bounding of "local" and "indigenous." Each narrative within this pantheon reflected the intersectional subject positions of its bearers and revealed their unique engagements with transforming social-ecological assemblages and systems. Ultimately, I was unsure about the functional value and the moral (and political) ramifications of presenting and in many ways extracting the required "data" from emergent and more-than-material renditions of climate-society relationships from critical social science and humanities scholarship. It seemed the lead authors were genuinely interested in pluralizing the process of knowledge production, while simultaneously being held accountable by a specific epistemic mandate. These conversations materialized over many months which coincided with the COVID-19 pandemic adding emotional and physical burden for a multidisciplinary team of scholars spread across the world. Three significant points emerged through these conversations. First, there is an emerging desire within the IPCC to engage with knowledges that are rooted in worldviews that differ significantly from euro-modern science. However, the rules of engagement are still being explored and are unlikely to remain constant across different reports. Second, some lead authors do understand and acknowledge the fundamental differences between indigenous knowledges and western science, and the disciplinary divergences between biophysical sciences and critical social science and humanities. Thus, they recognize the difficult (and possibly unethical) task of equitably representing them through a singular analytical framework. The inclusion of various social science and humanities scholarship in their reports is seen as a significant positive transformation towards addressing the dissonance. Third, while the IPCC process is open to engagement with different narratives of climate-society relationships, at present, such engagement is not a significant consideration when designing analytical pathways for the detection and attribution of climate change impacts. As I gradually became aware of these contingencies, I faced a key ethical dilemma: to engage with the IPCC with a transformational agenda, given its various shortcomings, or to walk away from it and allow its epistemological biases to endure?

In the end, I decided to stay. My choice (among other factors) was influenced by two important scholarly interventions: the first by Nightingale et al. (2019) who state that "The current techno-scientific apparatus guiding our responses to climate change is deeply disempowering for most people. There is a need to acknowledge the meaning and values of how climate change is made and experienced, and to incorporate this principle into the generation of knowledge through expert organizations such as the IPCC" (6) and second by Mathur (2015) who powerfully advocates for climate translators whose work would entail grounding "the Anthropocene within localized politics and ecosystems and can serve to relay the voices, imaginaries, and opinions of the communities, such as the residents of the Indian 
Himalaya" (83). Keeping these vital insights in mind, as I look back at the three different interactions presented here, I can situate them within their different subject positions. Ekta and Sunil's account represents an assemblage of human and more-than-human entities, material and more-than-material artifacts and processes, historical injustices, and inequities that produce the people and places of the Himalayas. Climate change is rarely voiced directly within this narrative but is often dissociated into different organic elements, many of which appear in conjunction with historically exploitative relationships between the powerful and the marginalized. For Sunil, the sacrifice of his father's life at the altar of national security exposes a historically unjust price that Himalayan communities have paid for the fulfillment of geopolitical ambitions (and insecurities) of the nation-state. As he puts it, "We are like ants, getting crushed under the feet of two angry, fighting elephants." Similarly, the burgeoning commercialization of land and various flora and fauna, ruining commons tended over generations and the explosion of infrastructure supporting extractive natural resource management, manufacturing, and energy industries reflect this similar culture of exploitation and abuse. Therefore, in Sunil's story, the fates of humans and non-humans in the Himalayas are deeply entangled, foreseeably hurtling towards an unsavory future effectively blurring the lines between nature and society. Climate change emerges in this narrative either as a manifestation of divine retribution aimed at reforming such an immoral world or as one of the many symptoms of human-nature disequilibrium, a symptom of a broken contract. For the scientists working at the confluence of global interest, public finance, and scientific discourse, climate change is their opportunity for legitimacy within the deeply hierarchical culture of global science. But, as techno-managerial representatives of the developmental state, which was an ex-colony and is now pursuing a certain vision of industrial capitalism, they are engaged in maintaining the historically rooted elite control over the reins of knowledge production. Furthermore, their invalidation and dismissal of "non-scientific" knowledge hint at the overwhelming acts of allegiance that the scientific worldview demands and the impact of such decisions. Finally, for the scientists working with the IPCC, the need to gather a wide range of scholarship on climate change is seen as a step towards inclusion and possibly democratization of the knowledge production process. However, the disconnect between considerably abstract notions of equity and justice and its potential translations into the empirical, analytical, and representational spheres of knowledge production, is significant. The IPCC still remains fairly biased towards epistemic tools emerging from reductionist, constituent ideologies; recognizes nation-states as the most important spatial units and fails to address the wider stakeholder community of non-state actors; and remains unable to conceptualize climate-society relationships that defy stark human-nature binaries. I believe that the IPCC process fails to address the enduring questions of justice and equity which are critical in the production of Himalayan climate-society relationships.

\section{Pasang: "Researchers come, ask questions, and leave"-extractive methodologies, community aspirations, and the politics of knowledge}

In northeast Nepal, the Mount Everest region attracts tens of thousands of tourists every year. It also attracts researchers pursuing different scientific projects from Himalayan glacial melt to Sherpa genetic makeup to the impact of tourism on the local community. When researchers come, middle-aged male hotel owners living on the main trail to Mount Everest like Dawa are invited to participate in various formal activities including meetings and knowledge-sharing 
workshops. Researchers communicate and engage community members in ways that are similar to the development and conservation practitioners that frequent the region.

In 2011, when I asked Dawa what he thinks of the researchers, he said quite bluntly, "they come, ask questions, and leave. They make money and never return. Researchers are just useless." Dawa's words of irritation rolled out of his tongue with ease, unguarded, during a casual conversation about climate change research I was interested in. Although his statement was not directly pointed at me, like many researchers he knew, I was asking questions, recording interviews, and taking notes for months without a visible, tangible, and immediate benefit to the local people. But I was also a fellow villager, somebody he knew personally. His words did not surprise me. It was not the first or the last time I heard someone complain about the "researcher-type" folks. In 2018, a woman from a village north of Dawa's shared that the villagers openly questioned the intentions of the researchers, who were hosting a lunch meeting to share their findings. The villagers mentioned that it was not apparent why they should care about the things the researchers were sharing. They were tired of seeing one group after another sharing findings of things that did not seem immediately relevant to them.

Several glacial studies have been conducted here for decades as documented by Sherpa (1999) and later by Sherpa (2012). Between 2004 and 2011, numerous climate change-related institutional activities were organized in the Everest region (Puschiasis 2015; Sherpa 2015), from the Nepali government's cabinet meeting to draw international attention to the melting Himalayas to a footrace to show that even the fastest runner will not be able to out-run the potential Imja glacial lake outburst flood (GLOF). In a BBC report (Khadka 2012), Ang Chhiri Sherpa, chairman of an association of tourism entrepreneurs in Pangboche and Dingboche, villages next to the critical Imja Tsho (glacial lake), said, "every time we begin to forget about the threats from glacial lake outburst, then comes news of yet another study through the radio and television, and this has been happening over and over again for more than 15 years now... Instead of having to fear death like that again and again, we would rather die once if the lake really bursts out one day."

Nearly 10 years after I had begun my ethnographic study of climate change in the Nepali Himalayas, the first-of-its-kind regional climate change assessment report was published (Wester, 2019). It was followed by the Intergovernmental Panel on Climate Change (IPCC) Special Report on the Oceanic and Cryospheric Change (SROCC) (IPCC 2019). Both of these reports showed that the melting of Himalayan glaciers was happening at a rate faster than previously estimated. To further discussions of the changing Himalayan cryosphere, the International Center for Integrated Mountain Development (ICIMOD) organized an international conference of experts and stakeholders in Kathmandu later that year.

An elected official from Langtang, a high-mountain region, listed the environmental changes his community had been noticing. His speech in Nepali, translated into English, highlighted how Kathmandu-based experts visit the region, write their reports based on limited stay, and bring "solutions" to problems that do not necessarily fit local conditions or are effective in the long run. The next day, a professional cheesemaker from the same village echoed the official's remarks and underscored the need for proper consultation with the villagers. He also pointed out, speaking in Nepali, that although he may not have an official university certificate, his long-term knowledge of the local environment is based on meticulous lifelong observation, first as a pastoralist and later as a cheesemaker.

When the event concluded, on my way home, a fellow Nepali participant confessed with embarrassment that she did not know what "cryosphere" really meant. She was not alone, however. Many participants including senior officials at the conference were frank about not 
fully understanding what "cryosphere" implied. As participants shared their experiences and observations from the high mountains, they were also learning and engaging with a new term that was gaining currency in framing international climate change science. The same place many people have called home for generations now had a new name.

At the heart of these recurring remarks in my ethnographic notes is the hierarchical approach with which urban "experts" have engaged the rural "locals." Even when community participation is emphasized in research projects, it takes the form of delivering the results to passive recipients at the backend rather than identifying problems with active stakeholders to address them together. The researchers sharing their findings in the field and consulting local communities as illustrated by the conference in Kathmandu show that efforts have been made to create platforms to share voices. However, as we see here, the need for a relational and reciprocal exchange instead of a short-term technical fix persists. Whereas the necessity for scientific research, especially in the context of climate change, cannot be over-stressed, it is crucial that our research projects recognize its extractive nature that is palpable for those experiencing it in the field. Dawa's words are a sharp reminder of that, and the work of repairing broken trust that remains.

\section{From climate adaptation to climate justice}

The significant publicity of "Climategate," the story about the IPCC's error regarding Himalayan glacier futures, its subsequent mitigation of the situation, and the wide range of responses the event elicited, highlights the complicated politics of climate change. While laying bare north-south relations, organizational culture, and the role of science in state-building, the event also highlights the nomination of certain subjects, worldviews, and scales as more important than others. IPCC's errors were seen by some to support a historical global north agenda to transfer an unequal share of the climate crisis burden onto the global south. The response to prevent future events was the creation of institutional mandates meant to reduce the space for epistemic and ontological plurality within the process of knowledge production. The credibility of the IPCC was seen restored despite unanswered questions around the negotiations of science and state when reasoning is tied to local political and subjective priorities. In all these conversations the solutions remain biased to the scale of the nation-state, claiming more stringently expert controlled knowledge production processes that avoid engaging with seemingly unquantifiable accounts while retaining the IPCC as the foremost arbitrator of climate futures (Beck, 2012; Mahony, 2014). The aftermath of "Climategate" resulted in significant public scrutiny and fueled a coalition of a diverse ensemble of climate deniers. To counter these attacks, the IPCC mobilized a powerful response highlighting their credibility through unfatigued allegiance to the scientific method (Hajer, 2012). This management ideology was echoed in the work of important Himalayan scholars who proposed that more quantifiable, more expert assessed, more technical research programs, harnessing the labor power of regional inhabitants (as citizen scientists), could address the controversies in knowledge production (Seidler and Bawa 2016; Singh and Thadani 2015). However, in such contestations around legitimacy and control, the questions of representation, plurality, and co-design/production are conspicuously absent and with it the voices of many like Ekta, Dawa, and Sunil. Himalayan people and places still shackled by environmental determinist renditions of risk denied their complicated stories of social-ecological transformation. It is these stories that confront tropes of precarity which are functions of temporally linear changes in biogeochemical cycles. 
Such linearity remains firmly entrenched in the ideology that addressing the "gaps in knowledge" through a focus on a reduction of uncertainties can progressively reduce our ignorance, and ultimately the increasing accumulation of knowledge will provide the adequate fodder for needed action and policy (Hulme, 2018). Much of this knowledge, produced and evaluated through decision support interfaces steeped in GIS-based climate impact visualization platforms and policy simulation models, digitize the governance of nature and create a "digital environmental politics," wielded and managed through mathematical algorithms (Machen and Nost, 2021). Such processes echo the fears of "objective" science in a "posttruth" era. They depend on scientific algorithms as respected arbitrators of credibility but end up marginalizing the multiplicity of climate knowledges while neglecting critical issues of responsibility and accountability in the science-policy debate.

So how do we move from this techno-managerial expert-driven, national state biased, conceptually reductionist (and generalizing) algorithm-driven culture of climate knowledge production, and policymaking? We realize this is a tall order and one that will require sustained interventions on many different levels by many different actors and institutions. However, inspired by regional mobilizations and emerging scholarship, we present a concise agenda for moving the focus from climate risk and its management to that of social-ecological wellbeing and justice (Ensor et al. 2019; Nightingale et al. 2019; Ojha 2020; Rampini 2017; Whyte 2020).

First, we need to move from extraction to co-production in regional climate change science and policy. Multiple scholars have noted the exploitative relationships that exist between normative climate change science and scientists and local/indigenous knowledge and practitioners (Ford et al. 2016; Klenk et al. 2017; Ojha et al. 2019). This unequal power dynamic is evident in scholarship that overwhelmingly "takes" local/indigenous knowledge, severs it from its socio-historical context, and inserts it within analytical and evaluation methodologies that contradict its cosmological characteristics. For Dawa and other members of his community, the lack of representation throughout the research process resembles the marginalization they face in governmentalized state spaces. The relationships they share with the state and the science begin to merge when the subjects representing each entity, intentionally or otherwise, marginalize them. Co-production of knowledge creates an alternative to this model by focusing on the politics of framing, advocating a plurality of assessment pathways, and embracing the massive uncertainty within climate-society relationships. This allows for the inclusion of not just material aspirations of the community but also the voices of more-than-human and morethan-material beings and processes through their intertwined stories (Gergan 2015).

Second, we need to situate climate change within a social and historical context. Climate change as a concept wields immense power in the Himalayan region (Chakraborty et al. 2019; Gergan, 2017; Satyal et al. 2017). However, as Sunil understands it, the intersections of oppression he occupies are all inseparable from each other. Accusing erratic rainfall or lack of winter snow as the main perpetrator is a "way of hiding our sins." The ongoing impacts of colonial land management and capitalism mimic the impacts of climate change. We need to be aware of this and not divorce the process of finding "fixes" to the climate problem from existing socio-political inequalities, which often lead our decision-making into the "technical trap" (Nightingale et al. 2019). The production of vulnerability to climatic events is coemergent with the existing inequities around caste, gender, class, age, religion, and political affiliations (Bhattarai 2019; Brown et al. 2017; Goodrich and Namchu 2019; Kovacs et al. 2016; Nagoda and Eriksen 2014). The detection and attribution of climatic change need to be reimagined using boundary objects that resemble the entangled social and ecological domains 
that, according to most Himalayan communities, are inseparable. Flash floods devastating a village are caused not simply by increasing monsoonal intensity, but also represent the hubris of top-down industrial infrastructure, the commodification of natural resource management, and the ebbing presence of communally managed land (Huber 2019; Huber et al., 2017). In this retelling, the boundary object is not simply safe precipitation values but a socionatural one: the mobile village of remittance households.

Third, we need to address the politics of scale (Ahlborg and Nightingale 2012; Barrett and Bosak 2018; Bergmann et al. 2011; Harris 2013; Ojha et al., 2020a, b). The Himalayas straddle two important socio-spatial processes that reveal how cultural, political, and ecological transformations are regionally woven together. First, colonial and post-colonial territorial politics were and are a product of ethnic, racial, and developmental insecurities. This has led to contentious encounters between regional governments around territorial autonomy and control, usually at the cost of social-ecological systems that defy political borders. Second, state-making has proceeded in most regional countries through the unveiling of hegemonic versions of nationalism. The corralling and subjugation of multicultural Himalayan people and places through tools such as national language imposition and widespread Anglophone instruction in educational institutions pose a significant threat to ecological and cultural wellbeing (see Davis et al. 2020). This prominence of the national scale, its political aspirations, and specific limitations pose a significant roadblock to equitable climate change-related decision-making. National plans to address climate-related issues foreground themselves in international political maneuvering between different collectives of state actors discussing national accountability, respective policies of carbon management, and the viability of a functional regulatory framework given outstanding issues of monitoring and evaluation (Nightingale 2018). Addressing this bias will require a move towards decentralization and polycentricity in governance. This can serve to improve the existing lack of stakeholder engagement in most top-down intergovernmental scenarios while providing a plurality of climate-society narratives that are brought forth by diverse scalar realities of regional communities. The inclusion of scholars working with feminist theories of science, political ecology, environmental history, human geography, environmental sociology, and anthropology among others can help with such a mobilization. Additionally, boundary making institutions like the IPCC can also facilitate this process by actively engaging with such polycentricity through an engagement with the fairly fragmented climate governance landscape of the Himalayas which is populated with all manner of hybrid institutions (e.g., public, private, civil society, community-based organizations).

Ultimately, the re-envisioning of a framework for climate justice will require institutions like the IPCC to become more reflexive and admit the limitations of their scale (state) and methodology (biophysical science bias). Simultaneously it will require the construction of other supplementary and complementary institutions and collectives that can navigate through the dynamic relational worlds of the Himalayas, which are not subservient to national territorial imaginaries. We hope that the required institutional reform is inspired, managed, and orchestrated by liberating the multitudes of climate-society relationships that are currently held hostage by the colonial and Cartesian walls of the Anthropocene.

Availability of data and material Not applicable

Code availability Not applicable 


\section{Declarations}

Competing interests The authors declare no competing interests.

\section{References}

Ahlborg H, Nightingale AJ (2012) Mismatch between scales of knowledge in Nepalese forestry: epistemology, power, and policy implications. Ecol Soc 17(4). https://doi.org/10.5751/ES-05171-170416

Awasthi, K., Khan, M. A., Sinha, S., Gupta, A., \& Mendiratta, N. (2016). Understanding the synergy between national mission for sustaining the Himalayan ecosystem and SAPCCs from Himalayan states

Barrett K, Bosak K (2018) The role of place in adapting to climate change: a case study from Ladakh, Western Himalayas. Sustainability (Switzerland) 10(4):1-22. https://doi.org/10.3390/su10040898

Beck S (2012) Between tribalism and trust: the IPCC under the public microscope. Nature and Culture 7(2):151173. https://doi.org/10.3167/nc.2012.070203

Beck S, Mahony M (2018) The IPCC and the new map of science and politics. Wiley Interdiscip Rev Clim Chang 9(6):1-16. https://doi.org/10.1002/wcc.547

Bergmann C, Gerwin M, Sax WS, Nüsser M (2011) Politics of scale in a high mountain border region: being mobile among the Bhotiyas of the Kumaon Himalaya, India. Nomadic Peoples 15(2):104-129. https://doi. org/10.3167/np.2011.150207

Bhattarai B (2019) How do gender relations shape a community's ability to adapt to climate change? Insights from Nepal's community forestry. Clim Dev 0(0):1-12. https://doi.org/10.1080/17565529.2019.1701971

Bremer S, Meisch S (2017) Co-production in climate change research: reviewing different perspectives. Wiley Interdiscip Rev Clim Chang 8(6):1-22. https://doi.org/10.1002/wcc.482

Brown T, Scrase TJ, Ganguly-Scrase R (2017) Globalised dreams, local constraints: migration and youth aspirations in an Indian regional town. Children's Geographies 15(5):531-544. https://doi.org/10.1080/ 14733285.2016.1274948

Campbell B (2017). Durham research online woodlands. European Bulletin of Himalayan Research (EBHR), Spring(49), 1-130

Carey M, James LC, Fuller HA (2014) A new social contract for the IPCC. Nat Clim Chang 4(12):1038-1039. https://doi.org/10.1038/nclimate2442

Chakraborty R, Daloz AS, Kumar M, Dimri AP (2019) Does awareness of climate change lead to worry? Exploring community perceptions through parallel analysis in rural Himalaya. Mt Res Dev 39(2). https://doi. org/10.1659/mrd-journal-d-19-00012.1

Chakraborty R, Gergan MD, Sherpa PY, Rampini C (2021) A plural climate studies framework for the Himalayas. Curr Opin Environ Sustain 51(February):42-54. https://doi.org/10.1016/j.cosust.2021.02.005

Davis AE, Gamble R, Roche G, Gawne L (2020) International relations and the Himalaya: connecting ecologies, cultures and geopolitics. Aust J Int Aff. https://doi.org/10.1080/10357718.2020.1787333

De Pryck K, Wanneau K (2017) (Anti)-boundary work in global environmental change research and assessment. Environ Sci Policy 77(April):203-210. https://doi.org/10.1016/j.envsci.2017.03.012

Drew G (2014) Mountain women, dams, and the gendered dimensions of environmental protest in the Garhwal Himalaya. Mt Res Dev 34(3):235-242 http://www.bioone.org/doi/10.1659/MRD-JOURNAL-D-13-00075.1

Ensor JE, Wennström P, Bhatterai A, Nightingale AJ, Eriksen S, Sillmann J (2019) Asking the right questions in adaptation research and practice: seeing beyond climate impacts in rural Nepal. Environ Sci Policy 94(January):227-236. https://doi.org/10.1016/j.envsci.2019.01.013

Ford JD, Cameron L, Rubis J, Maillet M, Nakashima D, Willox AC, Pearce T (2016) Including indigenous knowledge and experience in IPCC assessment reports. Nat Clim Chang 6(4):349-353. https://doi.org/10. $1038 /$ nclimate2954

Gergan MD (2015) Animating the sacred, sentient and spiritual in post-humanist and material geographies. Geogr Compass 9(5):262-275. https://doi.org/10.1111/gec3.12210

Gergan MD (2017) Living with earthquakes and angry deities at the Himalayan borderlands. Annals of the American Association of Geographers 107(2):490-498. https://doi.org/10.1080/24694452.2016.1209103

Gerlitz J-Y, Apablaza M, Hoermann B, Hunzai K, Bennett L (2015) A multidimensional poverty measure for the Hindu Kush-Himalayas, applied to selected districts in Nepal. Mt Res Dev 35(3):278-288. https://doi.org/ 10.1659/MRD-JOURNAL-D-14-00027.1

Goodrich CG, Namchu CV (2019) Identities, affiliations and gendered vulnerabilities in the mid-hills of West Bengal. Environmental Development 31(October 2018):78-87. https://doi.org/10.1016/j.envdev.2018.11.006 
Gustafsson KM, Berg M (2020) Early-career scientists in the Intergovernmental Panel on Climate Change. A moderate or radical path towards a deliberative future? Environmental Sociology 6(3):242-253. https://doi. org/10.1080/23251042.2020.1750094

Hajer MA (2012) A media storm in the world risk society: enacting scientific authority in the IPCC controversy (2009-10). Critical Policy Studies 6(4):452-464. https://doi.org/10.1080/19460171.2012.730758

Harris T (2013) Trading places: new economic geographies across Himalayan borderlands. Polit Geogr 35:6068. https://doi.org/10.1016/j.polgeo.2012.12.002

Hoppe R, Wesselink A, Cairns R (2013) Lost in the problem: the role of boundary organisations in the governance of climate change. Wiley Interdiscip Rev Clim Chang 4(4):283-300. https://doi.org/10.1002/wcc.225

Huber A (2019) Hydropower in the Himalayan hazardscape: strategic ignorance and the production of unequal risk. Water (Switzerland) 11(3). https://doi.org/10.3390/w11030414

Huber A, Gorostiza S, Kotsila P, Beltrán MJ, Armiero M (2017) Beyond "socially constructed" disasters: repoliticizing the debate on large dams through a political ecology of risk. Capital Nat Social 28(3):48-68. https://doi.org/10.1080/10455752.2016.1225222

Hulme M (2018) "Gaps" in climate change knowledge. Environmental Humanities 10(1):330-337. https://doi. org/10.1215/22011919-4385599

IHCAP (2016). Understanding the synergy between national mission for sustaining the Himalayan ecosystem and SAPCCs from Himalayan states. IHCAP. http://www.knowledgeportal-nmshe.in/Pdf/KnowReso_Pdf/ NMSHE\%20linkages\%20SAPCC_19\%20Jan\%202016.pdf

IPCC (2014) Climate change 2014: synthesis report. Contribution of Working Groups I, II and III to the Fifth Assessment Report of the Intergovernmental Panel on Climate Change [Core Writing Team, R.K. Pachauri and L.A. Meyer (eds.)]. IPCC, Geneva, Switzerland, 151 pp

IPCC (2019) IPCC special report on the ocean and cryosphere in a changing climate. In: Pörtner H-O, Roberts DC, Masson-Delmotte V, Zhai P, Tignor M, Poloczanska E, Mintenbeck K, Alegría A, Nicolai M, Okem A, Petzold J, Rama B, Weyer NM (eds) . IPCC, Geneva, Switzerland

Joshi S (2014) Environmental justice discourses in Indian climate politics. GeoJournal 79(6):677-691

Kala CP (2014) Deluge, disaster and development in Uttarakhand Himalayan region of India: challenges and lessons for disaster management. International Journal of Disaster Risk Reduction 8:143-152. https:/doi. org/10.1016/j.ijdrr.2014.03.002

Khadka N. (2012). Everest Sherpas in glacial lake study warning, Accessed April 11, 2020. https://www.bbc. com/news/science-environment-19569256

Klenk N, Fiume A, Meehan K, Gibbes C (2017) Local knowledge in climate adaptation research: moving knowledge frameworks from extraction to co-production. Wiley Interdiscip Rev Clim Chang 8(5). https:// doi.org/10.1002/wcc.475

Kovacs EK, Kumar C, Agarwal C, Adams WM, Hope RA, Vira B (2016) The politics of negotiation and implementation: a reciprocal water access agreement in the Himalayan foothills, India. Ecol Soc 21(2). https://doi.org/10.5751/ES-08462-210237

Livingston JE, Rummukainen M (2020) Taking science by surprise: the knowledge politics of the IPCC Special Report on 1.5 degrees. Environ Sci Policy 112(May):10-16. https://doi.org/10.1016/j.envsci.2020.05.020

Livingston JE, Lövbrand E, Alkan Olsson J (2018) From climates multiple to climate singular: maintaining policy-relevance in the IPCC synthesis report. Environ Sci Policy 90(October):83-90. https://doi.org/10. 1016/j.envsci.2018.10.003

Lord A, Drew G, Gergan MD (2020) Timescapes of Himalayan hydropower: promises, project life cycles, and precarities. Wiley Interdiscip Rev Water (June):1-15. https://doi.org/10.1002/wat2.1469

Mach KJ, Mastrandrea MD, Freeman PT, Field CB (2017) Unleashing expert judgment in assessment. Glob Environ Chang 44:1-14. https://doi.org/10.1016/j.gloenvcha.2017.02.005

Machen R, Nost E (2021) Thinking algorithmically: the making of hegemonic knowledge in climate governance. Trans Inst Br Geogr (April). https://doi.org/10.1111/tran.12441

Mahony M (2014) The IPCC and the geographies of credibility. History of Meteorology 6:95-112

Mathur N (2015) "It's a conspiracy theory and climate change " of beastly encounters and cervine dissapearances in Himalayan India. HAU: Journal of Ethnographic Theory 5(1):87-111

Minx JC, Callaghan M, Lamb WF, Garard J, Edenhofer O (2017) Learning about climate change solutions in the IPCC and beyond. Environ Sci Policy 77(May):252-259. https://doi.org/10.1016/j.envsci.2017.05.014

Mishra A, Agrawal N K, \& Gupta N (2017). Building mountain resilience: solutions from the Hindu Kush Himalaya. Retrieved from http://lib.icimod.org/record/33907\%

Nagoda S and Eriksen S, (2014). The role of local power relations in household vulnerability to climate change in Humla, Nepal. Climate change adaptation and development: transforming paradigms and practices. Routledge, New York, pp.200-218

Nightingale AJ (2016) Adaptive scholarship and situated knowledges? Hybrid methodologies and plural epistemologies in climate change adaptation research. Area 48(1):41-47. https://doi.org/10.1111/area.12195 
Nightingale AJ (2017) Power and politics in climate change adaptation efforts: struggles over authority and recognition in the context of political instability. Geoforum 84(May):11-20. https://doi.org/10.1016/j. geoforum.2017.05.011

Nightingale AJ (2018) The socioenvironmental state: political authority, subjects, and transformative socionatural change in an uncertain world. Environment and Planning E: Nature and Space 1(4):688-711. https://doi.org/ $10.1177 / 2514848618816467$

Nightingale AJ, Eriksen S, Taylor M, Forsyth T, Pelling M, Newsham A et al (2019) Beyond technical fixes: climate solutions and the great derangement. Clim Dev 0(0):1-10. https://doi.org/10.1080/17565529.2019. 1624495

Ojha HR (2020) Building an engaged Himalayan sustainability science. One Earth 3(5):534-538. https://doi.org/ 10.1016/j.oneear.2020.10.009

Ojha HR, Ghimire S, Pain A, Nightingale A, Khatri DB, Dhungana H (2016) Policy without politics: technocratic control of climate change adaptation policy making in Nepal. Clim Pol 16(4):415-433. https://doi.org/10.1080/14693062.2014.1003775

Ojha HR, Bhusal P, Paudel NS, Thompson PM, Sultana P (2019) Turning conflicts into cooperation? The role of adaptive learning and deliberation in managing natural resources conflicts in Nepal. Clim Pol 19(sup1): S107-S120. https://doi.org/10.1080/14693062.2018.1556240

Ojha H, Neupane KR, Pandey CL, Singh V, Bajracharya R, Dahal N (2020a) Scarcity amidst plenty: lower Himalayan cities struggling for water security. Water (Switzerland) 12(2). https://doi.org/10.3390/ w12020567

Ojha H, Regmi U, Shrestha KK, Paudel NS, Amatya SM, Zwi AB et al (2020b) Improving science-policy interface: lessons from the policy lab methodology in Nepal's community forest governance. Forest Policy Econ 114(2019):101997. https://doi.org/10.1016/j.forpol.2019.101997

Pearce W, Mahony M, Raman S (2018) Science advice for global challenges: learning from trade-offs in the IPCC. Environ Sci Policy 80(2017):125-131. https://doi.org/10.1016/j.envsci.2017.11.017

Poudel JM (2018) Pond becomes a lake: challenges posed by climate change in the trans-Himalayan regions of Nepal. Journal of Forest and Livelihood 16(1):87-102. https://doi.org/10.3126/jfl.v16i1.22884

Rampini C (2017) Environmental and climate justice along the Brahmaputra River in Northeast India. Lessons in Conservation 7:24

Sapkota P, Keenan RJ, Paschen JA, Ojha HR (2016) Social production of vulnerability to climate change in the rural middle hills of Nepal. J Rural Stud 48:53-64. https://doi.org/10.1016/j.jrurstud.2016.09.007

Satyal P, Shrestha K, Ojha H, Vira B, Adhikari J (2017) A new Himalayan crisis? Exploring transformative resilience pathways. Environmental Development 23(February):47-56. https://doi.org/10.1016/j.envdev. 2017.02.010

Seidler R, Bawa KS (2016) Ancient risks, current challenges in the Himalayas. Econ Polit Wkly 51(41):63-67

Sherpa L (1999) Human impacts on high-altitude forest structures in the Nangpa and Hinku, Sagarmatha and Makalu-Barun National Park. Doctoral Dissertation, University of Washington, Seattle, WA, Nepal

Sherpa PY. (2012). Sherpa perceptions of climate change and institutional responses in the Everest region of Nepal. [PhD dissertation]. Pullman, WA: Washington State University

Sherpa PY (2014) Climate change, perceptions, and social heterogeneity in Pharak, Mount Everest Region of Nepal. Hum Organ 73(2):153-161

Sherpa PY (2015) Institutional climate change adaptation efforts among the Sherpas of the Mount Everest region, Nepal. Res Econ Anthropol 35(3). https://doi.org/10.1108/S0190-128120150000035001

Singh SP, Thadani R (2015) Complexities and controversies in Himalayan research: a call for collaboration and rigor for better data. Mt Res Dev 35(4):401-409. https://doi.org/10.1659/MRD-JOURNAL-D-15-00045

Vardy M, Oppenheimer M, Dubash NK, O’Reilly J, Jamieson D (2017) The Intergovernmental Panel on Climate Change: challenges and opportunities. Annu Rev Environ Resour 42:55-75. https://doi.org/10.1146/ annurev-environ-102016-061053

Wester P (2019) In: Mishra A, Mukherji A, Shrestha AB (eds) The Hindu Kush Himalaya assessment: mountains, climate change, sustainability and people. Springer Nature, Switzerland

Whyte K (2020) Too late for indigenous climate justice: ecological and relational tipping points. Wiley Interdiscip Rev Clim Chang 11(1):1-7. https://doi.org/10.1002/wcc.603

Publisher's note Springer Nature remains neutral with regard to jurisdictional claims in published maps and institutional affiliations. 